\title{
Perbaikan Lintasan Produksi untuk Meningkatkan Efisiensi dengan Menghilangkan Bottleneck dan Penyeimbangan Lintasan pada Divisi Sewing
}

\author{
Yusuf Mauluddin ${ }^{1 *}$, Kurnia Yusup ${ }^{2}$, Erik Lesmana ${ }^{3}$ \\ 1,2,3Program Studi Teknik Industri, Institut Teknologi Garut, Garut, Indonesia \\ (*yusuf.mauluddin@itg.ac.id)
}

\begin{abstract}
Abstrak - Penelitian ini bertujuan untuk mendapatkan lintasan produksi pada divisi sewing yang seimbang dan efisien. Perbaikan lintasan tersebut dilakukan dengan menghilangkan bottleneck dan melakukan penyeimbangan lintasan. Metode studi gerakan Methods Time Measurement (MTM) digunakan untuk mengurai operasi yang menjadi bottleneck menjadi beberapa operasi. Untuk penyeimbangan lintasan digunakan lima metode heuristik yaitu Metode Bobot Posisi, Metode Pembebanan Berurut, Metode Wilayah, Metode Yamagumi Chart dan Metode Critical Path Method (CPM). Lintasan produksi yang dihasilkan dari kelima model tersebut kemudian dipilih yang memiliki efisiensi terbesar. Hasil penelitian memperlihatkan bahwa ada empat operasi yang menjadi bottleneck, kemudian setelah dilakukan studi gerakan dengan metode MTM diurai menjadi sepuluh operasi. Semula jumlah operasi pada lintasan produksi divisi sewing ada 20 operasi menjadi 26 operasi. Hasil penyeimbangan lintasan metode penyeimbangan lintasan paling baik adalah Metode Pembebanan Berurut yang menghasilkan jumlah stasiun terkecil dengan rata-rata efisiensi paling tinggi, yaitu 20 stasiun kerja dengan efisiensi $\mathbf{8 0 \%}$. Stasiun kerja hasil penyeimbangan lintasan, setelah diuji coba dengan menggunakan simulasi komputer, dapat mengefisiensikan proses di divisi sewing dengan menyelesaikan target produksi harian lebih cepat daripada lintasan produksi awal.
\end{abstract}

Kata kunci: bottleneck; Methods Time Measurement (MTM); penyeimbangan lintasan

\section{PENDAHULUAN}

PT X merupakan sebuah perusahaan yang memproduksi produk pakaian muslim. Salah satu produknya, yaitu gamis. Produk gamis tersebut merupakan pesanan dari salah satu perusahaan busana muslim terbesar di Indonesia. Untuk memenuhi pesanan tersebut, perusahaan menetapkan target produksi sebesar 120 pcs per hari dengan tujuh jam kerja, Pengerjaan produk tersebut dilakukan pada sebuah lintasan produksi. Lintasan produksi yang harus dilalui dalam pembuatan produk tersebut adalah divisi cutting, QC Cutting, bundeling, loading, sewing, QC Output, Bordir, finishing dan Packing. Setiap divisi dituntut untuk menyelesaikan pekerjaan sesuai target produksi yang ditetapkan, tetapi terkendala di divisi sewing yang belum dapat memenuhi target tersebut. Divisi tersebut harus menambah waktu lembur sampai dua jam lebih untuk bisa menyelesaikan 120 pcs per hari tersebut.

Pada divisi sewing terdapat 20 stasiun kerja yang ditangani oleh 20 orang operator. Pada divisi tersebut terlihat ada ketidakseimbangan beban kerja pada setiap operator seperti terlihat pada precedence diagram Gambar 1 dan Tabel 1 Pembagian operasi dan waktu operasi.

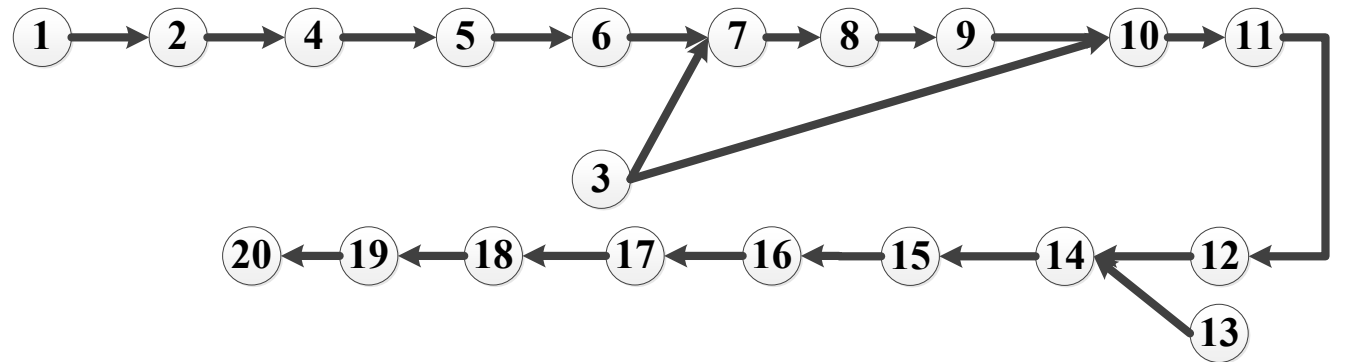

Gambar 1. Precedence diagram kondisi awal 
Tabel 1.

Pembagian operasi dan waktu operasi

\begin{tabular}{clc}
\hline Stasiun & \multicolumn{1}{c}{ Operasi } & $\begin{array}{c}\text { Waktu Operasi } \\
\text { (detik) }\end{array}$ \\
\hline 1 & Gabung Badan Belakang + Kupnat + Pasang Zipper & 146,5 \\
\hline 2 & Gabung Badan Depan + Tutup Zipper + Gabung Bahu & 184,4 \\
\hline 3 & Jahit Buat Rintik + Pasang Rintik + Pasang Stik & 265,6 \\
\hline 4 & Gabung Layer Depan + Jahit Klam Saku + Pasang Saku & 223,9 \\
\hline 5 & Pasang Variasi Bis (2x) + Stik Bis Badan & 241,1 \\
\hline 6 & Pasang Bis Variasi Bawah & 100,3 \\
\hline 7 & Rintik Variasi + Rintik Badan Tengah & 161,1 \\
\hline 8 & Gabung Variasi Bawah & 152,9 \\
\hline 9 & Obras Tangan + Saku + Bahu + Sambungan + Variasi & 161,6 \\
\hline & Bawah & 161,8 \\
\hline 10 & Jahit Pasang Tangan + Pasang Variasi Rintik Bawah & 212,6 \\
\hline 11 & Jahit Bagian Samping + Stik Variasi Bawah & 83,9 \\
\hline 13 & Obras Sisi & 97,5 \\
\hline 14 & Jahit Membuat Manset & 190,6 \\
\hline 15 & Pasang Manset + Pasang Stik & 185,7 \\
\hline 16 & Pasang Slit & 181,8 \\
\hline 17 & Clim Bawah + Atret Saku & 83,6 \\
\hline 18 & Klim Variasi Bawah + Layer + Tangan & 198 \\
\hline 19 & Tutup Corong Leher & 207 \\
\hline 20 & Stik Variasi Layer & 103,3 \\
\hline
\end{tabular}

Sumber: data perusahaan

Operasi pada salah satu stasiun terlihat lebih lama jika dibandingkan dengan stasiun yang lain dan sebaliknya. Hal tersebut menyebabkan terjadi bottleneck atau terjadi penumpukan barang sehingga menghambat aliran produksi. Bottleneck dapat juga diidentifikasi dengan membandingkan waktu operasi setiap stasiun dengan takt time untuk memenuhi target $120 \mathrm{pcs} /$ hari yaitu sebesar 210 detik per unit. Ada empat stasiun kerja yang memiliki waktu operasi melebihi takt time yaitu stasiun kerja 3, 4, 5, dan 11 .

Pada kenyataannya untuk mencapai 120 pcs per hari tersebut perusahaan memerlukan waktu tambahan dari tujuh jam waktu reguler dengan waktu kurang lebih tiga jam. Untuk itu, perlu dilakukan penelitian untuk menghilangkan bottleneck yang terjadi dan menyeimbangkan beban kerja pada setiap stasiun kerja agar lebih efisien dan target produksi tercapai.

\section{STUDI LITERATUR}

Permasalahan mengenai bottleneck pada lintasan produksi telah diteliti oleh para peneliti. Pada penelitian Hutomo (Hutomo, 2018) dilakukan pendekatan Theory Of Constraint dengan tidak menghilangkan bottleneck tetapi penambahan jam kerja agar pesanan dapat terpenuhi. Hal yang sama dilakukan pada penelitian Artati (Artati et al., 2020) yaitu tidak menghilangkan bottleneck tetapi melakukan simulasi terhadap beberapa alternatif solusi yang dapat meningkatkan kapasitas produksi. Kedua penelitian tersebut kurang sesuai dengan kasus yang terjadi di PT.X karena tidak menghilangkan bottleneck. Penelitian Mishan \& Tap (Mishan \& Tap, 2015) melakukan analisis studi gerakan dengan Method Time Measurement (MTM) pada stasiun bottleneck, dimana operasi yang menjadi bottleneck diurai menjadi beberapa operasi sehingga tidak menjadi tidak menjadi bottleneck lagi. Metode yang sama dilakukan juga pada penelitian Budiman et al (Budiman et al., 2019) dan Andriani(Andriani, 2017). Pendekatan metode MTM merupakan metode yang sesuai dengan kasus di PT X. Operasi yang melebihi takt time atau operasi bottleneck dengan metode MTM diurai menjadi beberapa operasi. Penguraian operasi tersebut menyebabkan perubahan pada precedence diagram sehingga harus dilakukan penyeimbangan lintasan.

Keseimbangan lintasan dalam aliran produksi mempengaruhi produksi dan produktivitas pada sebuah industri salah satunya berpengaruh terhadap output yang dihasilkan. Keseimbangan lintasan produksi yang tidak baik akan berakibat pada tingginya waktu dan biaya produksi serta tidak efektifnya penggunaan tenaga kerja. Penyeimbangan lintasan produksi memberikan manfaat untuk minimasi idle time dan jumlah stasiun 
(Gaspersz, 2004. Penyeimbang lintasan yang baik akan berpengaruh terhadap output yang dihasilkan (Baroto, 2002).

Secara umum metode penyeimbangan lintasan terdiri dari tiga metode (Baroto, 2002) yaitu metode heuristic, metode analitical dan metode simulasi. Metode heuristik lebih banyak digunakan karena lebih cepat dan lebih mudah digunakan. Terdapat tiga metode yang sering digunakan yaitu Metode Helgeson-Birnie atau Metode Bobot Posisi (Azwir \& Pratomo, 2017),(Dasanti et al., 2020). Metode Pembebanan Berurut (Handayani et al., 2016) dan Metode Wilayah (Nugrianto et al., 2020). Terdapat metode lain yang cukup sederhana dalam pegerjaannya yaitu metode Yamazumi Chart (Jeffrey.K, 2005). Metode heuristik lain yang dapat digunakan adalah pendekatan Metode CPM (Critical Path Method). Metode tersebut banyak digunakan pada kasus manajemen proyek (Maulana \& Kurniawan, 2019). Pendekatan metode CPM untuk penyeimbangan lintasan dapat dilakukan dengan syarat lintasan produksinya lurus, paralel dan berbentuk $\mathrm{U}$ (Boysen et al., 2007). Pada beberapa penelitian penerapan Metode CPM dapat meningkatkan efisiensi lintasan dan stasiun kerja yang efisien (Haq et al., 2017) (Mahajan \& Manoria, 2015). Masing-masing metode tersebut akan memberikan hasil yang mungkin sama atau berbeda, untuk itu perlu dicoba semua metode untuk mengetahui metode yang memberikan hasil yang lebih baik.

\section{METODOLOGI}

Untuk mencapai target takt time 210 detik per unit, langkah pertama; yaitu menghilangkan operasi yang menjadi bottleneck dengan mengurai operasi menjadi beberapa operasi. Kemudian langkah kedua dengan melakukan penyeimbangan lintasan. Pada langkah pertama, operasi-operasi yang menjadi bottleneck dilakukan studi gerakan dengan mengurai menjadi elemen-elemen gerakan sesuai dengan metode Methods Time Measurement (MTM). Peta tangan kiri dan tangan kanan digunakan untuk kegiatan tersebut. Kemudian dilakukan penggabungan beberapa elemen gerakan yang saling berhubungan sehingga membentuk operasi yang baru. Pembentukan operasi baru tersebut harus memiliki waktu operasi di bawah takt time. Operasioperasi yang baru tersebut akan membentuk precedence diagram yang baru.

Pada langkah kedua; dengan acuan precedence diagram yang baru, dilakukan penyeimbangan lintasan. Metode penyeimbangan lintasan yang digunakan dalam penelitian terdiri dari:

1. Metode Pembebanan Berurut (Gaspersz, 2004)

2. Metode Bobot Posisi (Heizer \& Barry, 2006)

3. Metode Wilayah (Gaspersz, 2004)

4. Metode Yamazumi Chart (Jeffrey.K, 2005)

5. Metode CPM (Heerkens, 2001)

Dari hasil penyeimbangan lintasan setiap metode, dipilih hasil penyeimbangan lintasan yang paling efisien dengan jumlah stasiun kerja yang minimal. Untuk mengetahui waktu penyelesaian produksi 120 pcs per hari sesuai dengan target, maka dilakukan simulasi komputer berdasarkan hasil penyeimbangan lintasan dari seluruh metode heuristic yang digunakan.

\section{HASIL DAN DISKUSI}

\section{A. Hasil Pengolahan Data dengan MTM}

Operasi yang melebihi dari takt time atau operasi bottleneck seperti pada Tabel 1, yaitu nomor operasi 3, 4, 5 dan 11. Setelah dilakukan analisa gerakan dengan MTM nomor operasi 3 dibagi menjadi tiga operasi baru, yaitu buat rintik, pasang rintik, dan pasang stik. Untuk nomor operasi 4 dibagi menjadi tiga operasi baru, yaitu jahit klim saku, pasang saku dan gabung layer depan. Nomor operasi 5 dibagi menjadi dua operasi baru, yaitu pasang variasi bis dan stik bis badan. Nomor operasi 11 dibagi menjadi dua operasi baru, yaitu jahit bagian samping dan stik variasi bawah. Metode MTM menghasilkan susunan operasi sebanyak 26 operasi dari yang semula 20 operasi seperti pada Tabel 2. Precedence diagram baru yang terbentuk dapat dilihat pada Gambar 2. 
Tabel 2

Hasil Metode MTM

\begin{tabular}{cclc}
\hline $\begin{array}{c}\text { No Operasi } \\
\text { Awal }\end{array}$ & $\begin{array}{c}\text { No Operasi } \\
\text { Baru }\end{array}$ & \multicolumn{1}{c}{ Operasi Baru } & Waktu Operasi \\
\hline 1 & 1 & Gabung Badan Belakang + Kupnat + Pasang Zipper & 146,5 \\
2 & 2 & Gabung Badan Depan + Tutup Zipper + Gabung Bahu & 184,4 \\
3 & 3 & Buat Rintik & 150,5 \\
& 4 & Pasang Rintik & 54,8 \\
& 5 & Pasang Stik & 60,2 \\
4 & 6 & Jahit Klim Saku & 72,8 \\
& 7 & Pasang Saku & 73,6 \\
& 8 & Gabung Layer Depan & 77,5 \\
5 & 9 & Pasang Variasi Bis & 185,9 \\
& 10 & Stik Bis Badan & 55,2 \\
6 & 11 & Pasang Bis Variasi Bawah & 100,3 \\
7 & 12 & Rintik Variasi + Rintik Badan Tengah & 161,1 \\
8 & 13 & Gabung Variasi Bawah & 152,9 \\
9 & 14 & Obras Tangan + Saku + Bahu + Sambungan + Variasi Bawah & 161,6 \\
10 & 15 & Jahit Pasang Tangan + Pasang Variasi Rintik Bawah & 161,8 \\
11 & 16 & Jahit Bagian Samping & 109,7 \\
& 17 & Stik Variasi Bawah & 102,9 \\
12 & 18 & Obras Sisi & 83,9 \\
13 & 19 & Jahit Membuat Manset & 97,5 \\
14 & 20 & Pasang Manset + Pasang Stik & 190,6 \\
15 & 21 & Pasang Slit & 185,7 \\
16 & 22 & Klim Bawah + Atret Saku & 181,8 \\
17 & 23 & Corong Leher & 83,6 \\
18 & 24 & Klim Variasi Bawah + Layer + Tangan & 198 \\
19 & 25 & Tutup Corong Leher & 207 \\
20 & 26 & Stik Variasi Layer & 103,3 \\
\hline
\end{tabular}

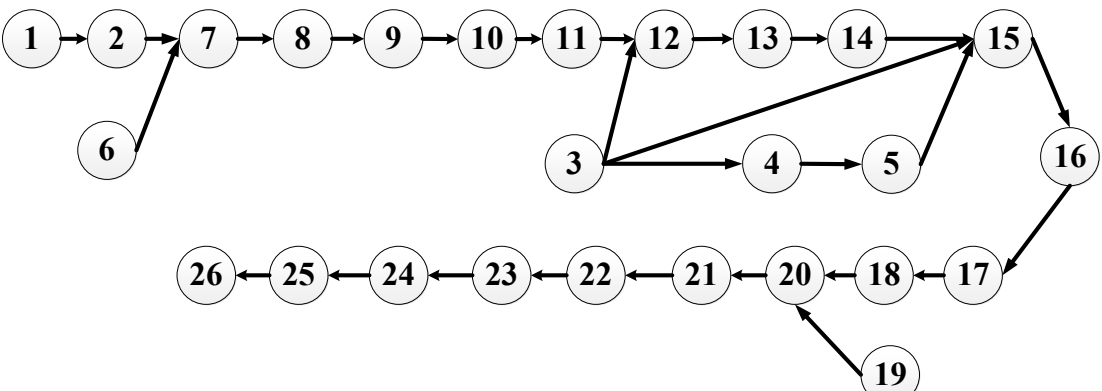

Gambar 2. Precedence diagram hasil Metode MTM

\section{B. Hasil Penyeimbangan Lintasan}

1. Penyeimbangan Lintasan dengan Metode Pembebanan Berurut

Berdasarkan Gambar 3, penyeimbangan lintasan dengan Metode Pembebanan Berurut menghasilkan jumlah stasiun kerja sebanyak 20 dengan rata-rata efisiensi lintasan sebesar $80 \%$.

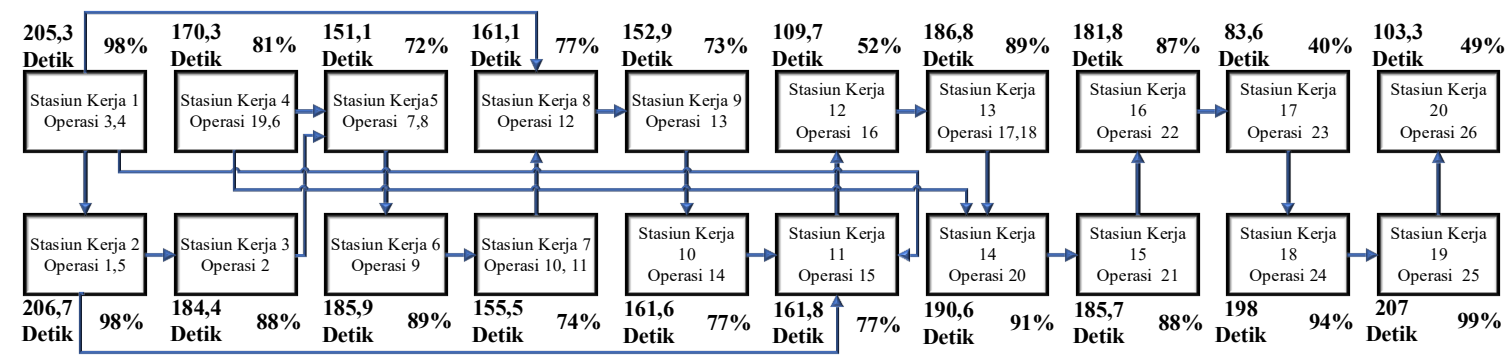

Gambar 3. Hasil penyeimbangan lintasan dengan Metode Pembebanan Berurut 
2. Penyeimbangan Lintasan dengan Metode Bobot Posisi

Berdasarkan Gambar 4, penyeimbangan lintasan dengan Metode Bobot Posisi menghasilkan jumlah stasiun kerja sebanyak 22 dengan rata-rata efisiensi lintasan sebesar $72 \%$.

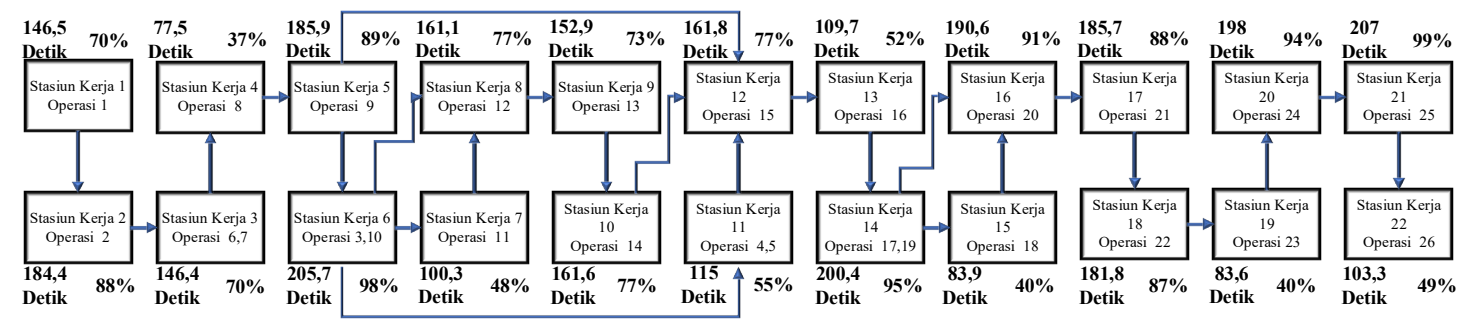

Gambar 4. Hasil penyeimbangan lintasan dengan Metode Bobot Posisi

3. Penyeimbangan Lintasan dengan Metode Wilayah

Berdasarkan Gambar 5, penyeimbangan lintasan dengan Metode Wilayah menghasilkan jumlah stasiun kerja sebanyak 21 dengan rata-rata efisiensi lintasan sebesar $76 \%$.

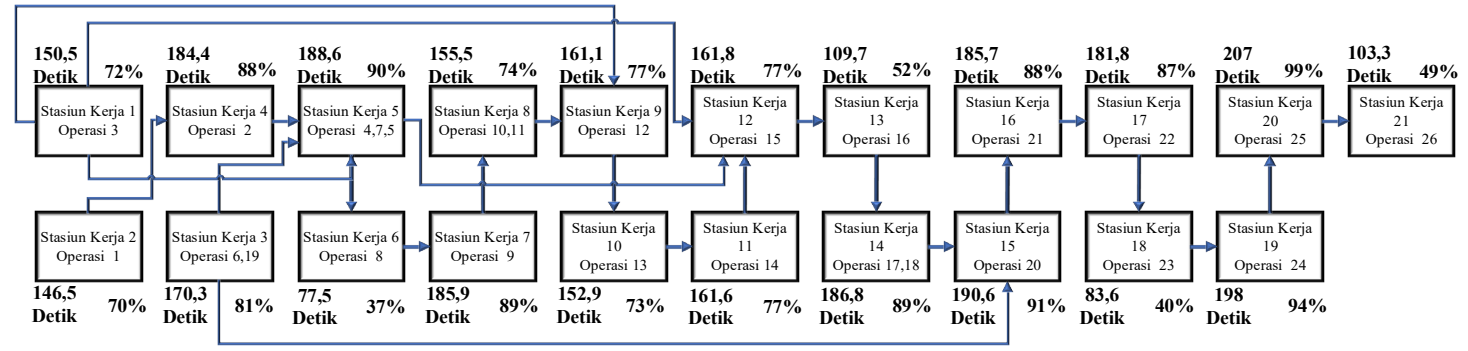

Gambar 5. Hasil penyeimbangan lintasan dengan Metode Wilayah

4. Penyeimbangan Lintasan dengan Metode Yamazumi Chart

Berdasarkan Gambar 6, penyeimbangan lintasan dengan Metode Yamazumi Chart menghasilkan jumlah stasiun kerja sebanyak 22 dengan rata-rata efisiensi lintasan sebesar $72 \%$.

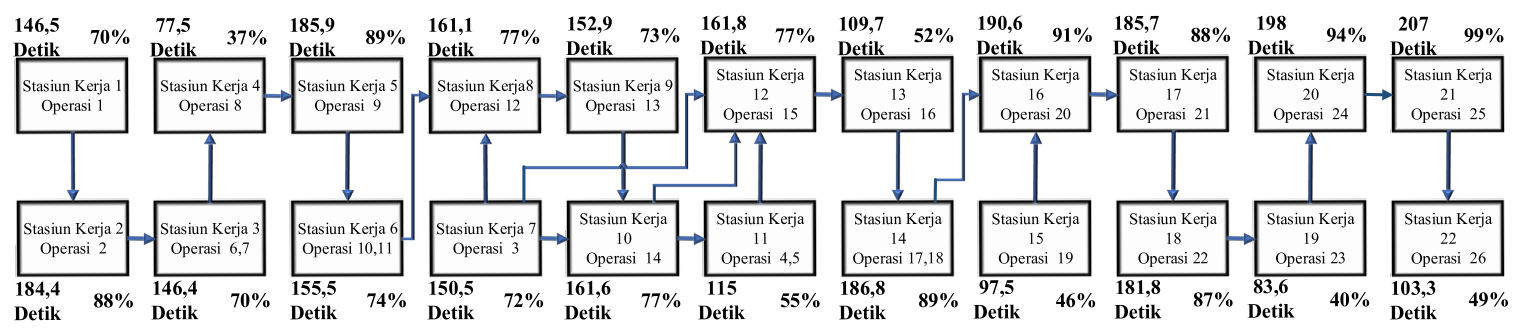

Gambar 6. Hasil penyeimbangan lintasan dengan Metode Yamazumi Chart

5. Penyeimbangan Lintasan dengan Critical Path Method

Berdasarkan Gambar 7, penyeimbangan lintasan dengan Critical Path Method menghasilkan jumlah stasiun kerja sebanyak 22 dengan rata-rata efisiensi lintasan sebesar $72 \%$.

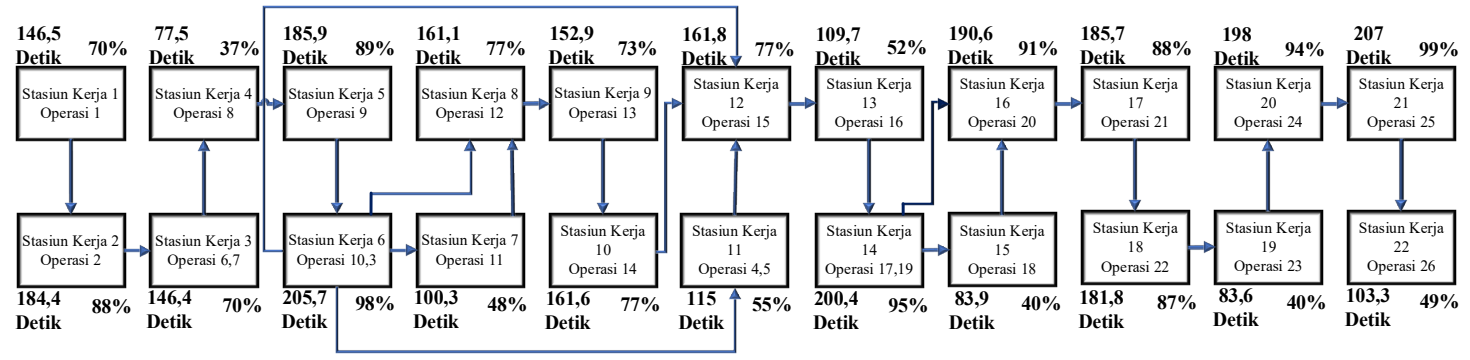

Gambar 7. Hasil penyeimbangan lintasan dengan Critical Path Method 


\section{Analisis Hasil}

\section{Analisis Hasil Metode MTM}

Perbaikan atau penghilangan bottleneck dengan menggunakan MTM menunjukkan terdapat penambahan operasi dari kondisi aktual sebanyak 20 operasi menjadi 26 operasi. Penambahan 6 operasi ini terjadi dari penguraian operasi yang mengalami bottleneck. Penguraian operasi yang menjadi bottleneck menjadi beberapa operasi, tidak mengurangi aktivitas yang harus dilakukan pada pembuatan produk gamis, sehingga total waktu pembuatan produk tetap sama. Sebagai contoh, operasi 3 pada lintasan produksi awal mempunyai waktu proses 265,6 detik, diubah menjadi tiga operasi yaitu operasi 3, operasi 4 dan operasi 5 dengan waktu operasi 150,5 detik, 54,8 detik dan 60,2 detik, jika dijumlahkan akan relatif sama dengan waktu operasi 3 sebelumnya. Waktu seluruh operasi dari lintasan produksi yang baru menjadi lebih kecil dari takt time yang ditargetkan. Waktu operasi yang baru menjadi lebih kecil. Waktu operasi terbesar dari lintasan produksi yang baru yaitu operasi 20 sebesar 190,6 detik, masih di bawah takt time.

2. Analisis Hasil Penyeimbangan Lintasan

Penyeimbangan lintasan yang dilakukan dengan menggunakan beberapa metode heuristik, memberikan hasil yang berbeda-beda seperti terlihat pada Tabel 3.

Tabel 3

Analisis hasil metode penyeimbangan lintasan

\begin{tabular}{llll}
\hline No & Metode & Stasiun & Efisiensi \\
\hline 1 & Bobot Posisi & 22 & $72 \%$ \\
$\mathbf{2}$ & Pembebanan Berurut & $\mathbf{2 0}$ & $\mathbf{8 0 \%}$ \\
3 & Wilayah & 21 & $76 \%$ \\
4 & Yamazumi Chart & 22 & $72 \%$ \\
5 & Critical Path Method (CPM) & 22 & $72 \%$ \\
\hline
\end{tabular}

Berdasarkan Tabel 3, dapat diketahui bahwa semua hasil penyeimbangan dapat diimplementasikan di perusahaan karena tidak mengalami Bottleneck dan Backtracking. Berdasarkan hasil tersebut maka hasil Metode Pembebanan Berurut menghasilkan jumlah stasiun kerja terkecil dengan nilai efisiensi terbesar. Metode yang dipilih tersebut berbeda dengan penelitian (Azwir \& Pratomo, 2017) dan (Mahajan \& Manoria, 2015) dimana Metode Bobot Posisi dan Critical Path Method yang terpilih. Hal tersebut membuktikan bahwa suatu metode heuristik belum tentu terbaik pada kasus yang lain.

Metode Pembebanan Berurut menghasilkan 20 stasiun kerja sama halnya dengan jumlah stasiun awal sehingga tidak perlu menambah operator baru. Aktivitas yang masih sama dengan lintasan lama ada 12 stasiun kerja, 7 stasiun kerja dengan nama sama, yaitu 14 - 20 stasiun kerja dan 5 stasiun kerja aktivitas sama dengan nama stasiun kerja yang berbeda. Delapan stasiun kerja yang berbeda akibat dari penguraian operasi hasil dari metode MTM. Terlihat bahwa penguraian operasi bottleneck, berhasil merubah lintasan produksi yang tidak seimbang menjadi lebih seimbang.

Untuk mengetahui apakan hasil penyeimbangan lintasan tersebut dapat bekerja sesuai target produksi yang ditetapkan, perlu dilakukan analisis lanjutan dengan menggunakan simulasi komputer (Salim et al., 2016). Aplikasi yang digunakan adalah Software Anylogic. Simulasi dijalankan untuk memproses 120 pcs produk sesuai dengan target produksi. Output yang digunakan adalah waktu penyelesaian seluruh produk. Hasil analisis simulasi tersebut ditampilkan pada Tabel 4.

Tabel 4

Analisis hasil simulasi

\begin{tabular}{lcc}
\hline \multirow{2}{*}{ Metode } & \multicolumn{2}{c}{ Waktu Penyelesaian } \\
\cline { 2 - 3 } & Menit & Jam \\
\hline Kondisi Aktual & 584,17 & 9,74 \\
\hline Lintasan Produksi Baru & 466,85 & 7,78 \\
\hline
\end{tabular}

Berdasarkan Tabel 4, terlihat hasil simulasi komputer pada kondisi aktual sebelum dilakukan penyeimbangan lintasan menunjukkan lintasan tersebut memerlukan waktu 9,74 jam untuk menyelesaikan 120 produk, hasil tersebut relatif sama dengan kondisi nyata, dimana waktu penyelesaian memerlukan waktu lembur selama 2,74 jam. Hasil simulasi komputer dari penyeimbangan lintasan dengan metode heuristik 
memberikan hasil waktu 7,78 jam, sehingga waktu lembur rata-rata selama 0,78 jam. Hasil tersebut menghasilkan penurunan untuk waktu lembur sebesar 1,96 jam.

\section{KESIMPULAN}

Permasalahan bottleneck pada PT X dapat diselesaikan dengan metode MTM. Operasi yang menjadi bottleneck ada 4 operasi yang kemudian dengan metode tersebut diurai menjadi 10 operasi dengan waktu operasi di bawah takt time. Kegiatan tersebut menyebabkan terbentuknya lintasan produksi yang baru. Penyeimbangan lintasan yang dilakukan dengan menggunakan metode heuristik meningkatkan efisiensi lintasan. Penyeimbangan lintasan dengan Metode Pembebanan Berurut memiliki jumlah stasiun kerja yang terkecil dan efisiensi lintasan yang terbaik, yaitu $80 \%$. Pemenuhan target harian perusahaan dapat diperoleh dengan penambahan jam kerja 0,78 jam dan dapat melakukan pengurangan lembur jam kerja dari semula selama 2,754 jam.

Pada penelitian ini, bottleneck diidentifikasi sebagai operasi yang melebihi takt time. Jika batas takt time berubah lebih besar atau lebih kecil, akan menarik untuk dijadikan penelitian lebih lanjut. Perubahan tersebut tentu akan mengakibatkan keseimbangan lintasan pun berubah. Metode heuristic yang terpilih mungkin akan berubah. Pada penelitian yang akan datang akan perlu diteliti penyeimbangan lintasan dengan menggunakan model matematis agar diketahui yang optimum.

\section{DAFTAR PUSTAKA}

Andriani, D. P. (2017). Penentuan Waktu dan Output Baku Pada Proses Produksi Tube Lamp Dengan Methods Time Measurement. Sinergi, 21(3), 204.

Artati, N., Soleh, M., \& Amri, F. (2020). Simulasi Pro-Model dan Optimasi Produksi dan Reduksi. 1, 7-20.

Azwir, H. H., \& Pratomo, H. W. (2017). Implementasi Line Balancing untuk Peningkatan Efisiensi di Line Welding Studi Kasus: PT X. Jurnal Rekayasa Sistem Industri, 6(1), 57.

Baroto, T. (2002). Perencanaan dan Pengendalian Produksi. Ghalia Indonesia.

Boysen, N., Fliedner, M., \& Scholl, A. (2007). A Classification of Assembly Line Balancing Problems. European Journal of Operational Research, 183, 674-693. https://doi.org/10.1016/j.ejor.2006.10.010

Budiman, I., Sembiring, A. C., Tampubolon, J., Wahyuni, D., \& Dharmala, A. (2019). Improving Effectiveness and Efficiency of Assembly Line With a Stopwatch Time Study and Balancing Activity Elements. Journal of Physics: Conference Series, 1230(1).

Dasanti, A.F., Jakdan, F., \& Santoso, T. (2020). Penerapan Konsep Line Balancing Untuk Mencapai Efisiensi Kerja yang Optimal Pada Setiap Stasiun Kerja Di PT Garment Jakarta. Bulletin of Applied Industrial Engineering Theory, 2(1), 2-7.

Gaspersz, V. (2004). Operation Planning and Inventory Control. PT Gramedia Pustaka Utama.

Handayani, D. Y., Prihandono, B., \& Kiftiah, M. (2016). Analisis Metode Moodie Young Dalam Menentukan Keseimbangan Lintasan Produksi . Buletin Ilmiah Mat. Stat. Dan Terapannya (Bimaster), 5(03), 229238.

Haq, W. U., Kaushik, A., \& Taquee, M. (2017). An Improvement in Assembly line Balancing Problem Using Critical Path Model. International Journal of Advanced Research and Development, 2(5), 382-387.

Heerkens, G. R. (2001). Project Management. McGraw-Hill.

Heizer, J., \& Barry, R. (2006). Operation Management (7th ed.). Salemba Empat.

Hutomo, D. F. (2018). Analisa Bottleneck Pada Produk Kap Lampu RM 238 dengan Pendekatan Theory of Contstrain di PR. XYZ. In Director. Universitas Pembangunan Nasional Veteran.

Jeffrey.K, L. (2005). The Toyota Way. Erlangga.

Mahajan, P., \& Manoria, A. (2015). Balancing The Line By Using Heuristic Method Based On Cpm In SALBP - A Case Study. IJRET: International Journal of Research in Engineering and Technology, 04(12), 7680.

Maulana, A., \& Kurniawan, F. (2019). Time Optimization Using Cpm, Pert And Pdm Methods In The Social And Department Of Kelautan Building Development Project Gresik District. IJTI(International Journal Of Transportation and Infrastruktur, 2(2), 58-67.

Mishan, N. N., \& Tap, M. M. (2015). Increasing Line Efficiency By Using Timestudy and Line Balancing in 
a Food Manufacturing Company. Jurnal Mekanikal, 38, 32-43.

Nugrianto, G., Syambas, M., Diky, R., \& Demus, N. (2020). Analisis Penerapan Line Balancing untuk Peningkatan Efisiensi pada Proses Produksi Pembuatan Pagar Besi Studi Kasus: CV . Bumen Las Kontraktor. Bulletin of Applied Industrial Engineering Theory, 2(1).

Salim, H. K., Setiawan, K., \& Hartanti, L. P. (2016). Perancangan Keseimbangan Lintasan Produksi Menggunakan Pendekatan Simulasi Dan Metode Ranked Positional Weights. J@Ti Undip : Jurnal Teknik Industri, 11(1), 53-60. 